\title{
Cancer Screening Practices Among Physicians in the National Breast and Cervical Cancer Early Detection Program
}

\author{
Vicki B. Benard, Ph.D., ${ }^{1}$ Mona S. Saraiya, M.D., M.P.H., Ashwini Soman, Katherine B. Roland, M.P.H., \\ K. Robin Yabroff, Ph.D., M.B.A., ${ }^{2}$ and Jackie Miller, M.D.'
}

\begin{abstract}
Background: The National Breast and Cervical Cancer Early Detection Program (NBCCEDP) provides lowincome, uninsured women with screening and diagnostic services for breast and cervical cancer. Our study was conducted to describe the demographic and practice characteristics of participating and nonparticipating physicians, as well as their beliefs, adoption of new screening technologies, and recommendations for breast and cervical cancer screening.

Methods: From a 2006-2007 nationally representative survey, we identified 1,111 practicing primary care physicians who provide breast and cervical cancer screenings and assessed their recommendations using clinical vignettes related to screening initiation, frequency, and cessation. Responses of physicians participating in the NBCCEDP were compared with those from nonparticipating physicians.

Results: Of the physicians surveyed, 15\% reported participation in the NBCCEDP, $65 \%$ were not participants, and $20 \%$ were not sure or did not respond to this question. Program physicians were significantly more likely to practice in multispecialty settings, in a rural location, and in a hospital or clinic setting and had more patients who were female and insured by Medicaid or uninsured compared with nonprogram physicians. Beliefs about the effectiveness of screening tools or procedures in reducing breast or cervical cancer mortality were similar by program participation. Adoption of new technologies, including digital mammography and human papillomavirus (HPV) testing, and making guideline-consistent recommendations for screening initiation, frequency, and cessation did not differ significantly by program participation.

Conclusions: Although there may be differences in physician characteristics and practice settings, the beliefs and screening practices for both breast and cervical cancer are similar between program and nonprogram providers.
\end{abstract}

\section{Introduction}

I N THE United StATES, low-income women have poorer breast and cervical cancer survival and mortality outcomes compared with women with higher incomes. ${ }^{1,2}$ The National Breast and Cervical Cancer Early Detection Program (NBCCEDP), administered by the Centers for Disease Control and Prevention (CDC), helps low-income, uninsured women receive screening and diagnostic services for breast and cervical cancer through cooperative agreements that fund state and territorial health departments, tribes, and tribal organizations to provide these services. Since its inception in 1991, over 3.7 million women have been screened through the NBCCEDP, and 44,885 cases of breast cancer, 123,563 cervical precursor lesions, and 2,554 cervical cancers have been detected. ${ }^{3}$ Currently, the NBCCEDP is funding screening programs in 50 states, the District of Columbia, 5 U.S. territories, and 12 tribal programs.

The NBCCEDP is served by more than 20,000 primary care physicians nationwide. In each location, the program is responsible for establishing its own network of physicians willing to serve low-income women with a reimbursement structure capped at Medicare rates. Because the network is developed locally, the physicians are representative of the community in which they reside, and their cervical cancer screening practices are representative of general practices within their clinical specialty. ${ }^{4}$ In general, NBCCEDP policy decisions concerning which services to reimburse have been consistent with

\footnotetext{
${ }^{1}$ Division of Cancer Prevention and Control, Centers for Disease Control and Prevention, Atlanta, Georgia.

${ }^{2}$ Division of Cancer Control and Population Sciences, National Cancer Institute, Bethesda, Maryland.
} 
recommendations of the U.S. Preventive Service Task Force (USPSTF) regarding age to begin screening and frequency of screening. ${ }^{5}$ Many new technologies have been implemented for both breast and cervical cancer screening since the inception of the national program, including liquid-based cytology (LBC) ${ }^{6}$ and human papillomavirus (HPV) DNA testing (as a reflex or cotest $)^{7}$ for cervical cancer screening and digital mammography for breast cancer screening. ${ }^{8,9}$ Based on expert panel reviews and recommendations, the NBCCEDP began reimbursing for LBC in 2006, HPV DNA testing (for management only) in 2003, and digital mammography in 2009.

Only one previous national survey in 2004 compared demographic and patient characteristics and screening practices of NBCCEDP physicians with physicians who do not participate in the program ${ }^{4}$; however, that survey was limited to program physicians who performed only cervical cancer screening. In this earlier study, Saraiya et al. ${ }^{4}$ found program physicians to be well equipped to serve women at the highest risk of cervical cancer because they were more likely than nonprogram providers to serve racially diverse, uninsured, publicly insured, and rural patients. To date, there has not been an analysis of demographic characteristics and screening practices of program physicians who perform breast cancer screening. The goal of our study was to survey program and nonprogram physicians to provide updated data about cervical cancer screening practices and current information about breast cancer screening recommendations among program physicians compared with nonprogram physicians.

\section{Materials and Methods}

From August 2006 to May 2007, a nationally representative sample of practicing primary care physicians was surveyed regarding their breast, cervical, colorectal, and lung cancer screening recommendations and practices using a split sample design. Further information about the sampling and survey design has been provided elsewhere. ${ }^{10,11}$ This study was approved by the Institutional Review Board (IRB) of WESTAT (www.westat.com), the contractor administering the survey, and by the U.S. Office of Management and Budget. The protocol was determined to be exempted from CDC and National Institutes of Health (NIH) IRB review.

\section{Population}

The physician master file of the American Medical Association (AMA) was used as a sampling frame to identify primary care physicians for this national survey. Physicians were randomly selected from a stratified sample, with physician specialty as the sampling strata. The only specialties considered were those with the scope of substantial engagement in cancer screening, including family practice, general practice, obstetrics and gynecology, and internal medicine. The questionnaire on breast and cervical cancer screening was completed by 1,212 physicians; the response rate was $67.5 \%$. For this study, the sample was restricted to 1,111 primary care physicians who reported providing or referring both screening Pap tests and mammograms or clinical breast examinations (CBEs) to at least one asymptomatic, average-risk patient per month.

\section{Measures}

We selected measures of physician and practice characteristics that have been shown elsewhere to be associated with practice patterns, and we identified other novel measures that we hypothesized were associated with reported screening practice. The primary outcome measure was whether the provider currently participated in the NBCCEDP (yes, no, or don't know). Because the don't know group was not similar to either the yes or no category for all other variables, these physicians are described in a footnote in each table. Physician characteristics measured included age, gender, race, if an international medical school graduate, years since medical school graduation, board certification, and affiliation, if any, with a medical school. Practice characteristics measured included urban/rural designation based on location of practice, practice type (solo, single specialty group, multispecialty group), main primary care practice setting (physician-owned practice; employee of large medical group, healthcare system or health maintenance organization [HMO]; employee of a university, hospital, or other clinic), proportion of all time spent providing primary care, percentage of female patients seen in practice, percentage of patients insured by Medicaid, and percentage of patients uninsured.

The survey also assessed whether the primary care practice had used patient (mail, telephone call, e-mail, and personalized web page) or physician (chart or computerized-prompt, flow sheet) reminders for screening. Because we were interested in the systematic use of reminders, we did not classify responses of verbal prompt at office visit or review of the medical record at the time of visit as being either a patient or physician reminder. We also assessed the type of medical record system: paper chart, partial electronic medical record (EMR), in transition from paper to full EMR, and full EMR.

Breast and cervical cancer screening beliefs included beliefs about the effectiveness of CBEs, mammography, digital mammography, conventional Pap test, and LBC in reducing cancer mortality and which screening guidelines-USPSTF, American Cancer Society (ACS), and American College of Obstetricians and Gynecologists (ACOG) —-were influential to their practices.

Breast and cervical cancer screening practices included adoption of new technologies (specifically digital mammography, LBC, and HPV DNA test) and screening practices. Screening recommendations were assessed with clinical vignettes related to screening initiation, frequency, and cessation. These vignettes were cognitively tested in physicians before fielding the survey. The vignettes included the woman's age, screening history, and health status. For each vignette, physicians were asked what screening they would recommend at the next routine office visit.

\section{Breast cancer vignettes}

A breast cancer vignette related to frequency of screening by mammography was asked for women $\geq 40$ years of age; guideline-consistent responses for the time of the study (20062007) were every 1-2 years for women 40-49 years old and annually for women $\geq 50$ years. ${ }^{12-14}$ Another vignette, related to cessation of breast cancer screening, presented a woman with lung cancer whose expected survival may be shortened and would not benefit from early detection; guidelineconsistent response would not recommend screening, based on current health status. ${ }^{13}$ 


\section{Cervical cancer vignettes}

The first vignette regarding screening initiation for cervical cancer described an 18-year-old woman who had never had sexual intercourse, coming to her first gynecologic examination. A guideline-consistent response in this case is either no Pap screening or a Pap test at age 21 years. $6,15,16$

The second vignette related to screening frequency for a 35year-old woman who had had no new sexual partners in the preceding 5 years and three consecutive negative Pap tests. A guideline-consistent response for this woman was a Pap test every 2-3 years. ${ }^{6,15}$ Two additional vignettes were presented on the topic of cervical cancer screening cessation. One presented a 35-year-old woman with a history of a hysterectomy (for benign reasons); the other presented a 66-year-old woman with lung cancer and three consecutive normal Pap test results. The guideline-consistent responses for both were to withhold screening. ${ }^{6,15}$ Exact wording of all survey items is available at healthservices.cancer.gov/surveys/screening_rp/.

\section{Data analysis}

We performed stratified analyses by NBCCEDP participation to examine the differences among physician demographics, their practice characteristics, and their screening beliefs and recommendations. Estimates and 95\% confidence intervals (CI) were computed for each strata. Chi-square tests with $p$ values were performed to test for overall association between program participation and demographic and practicerelated covariates. For variables that were significantly associated with program participation, we did pairwise contract testing (with $t$ tests) to detect differences by groups. The statistical analyses were performed using SUDAAN version 9.1 (Research Triangle Institute, Research Triangle Park, NC) to account for the stratified survey design, the sampling weights, and nonresponse.

\section{Results}

Of the 1,111 physicians included in our sample, we estimate $15 \%$ participated in the NBCCEDP, $65 \%$ were not participants, and $20 \%$ were not sure or did not indicate whether or not they participated. Compared with nonprogram physicians, program physicians were significantly more likely to be female, non-Hispanic white, obstetricians/gynecologists, and affiliated with a medical school (Table 1).

Compared with nonprogram physicians, program physicians were significantly more likely to work in a multispecialty practice, practice in rural communities, spend less time providing primary care, and be an employee in a hospital or clinic setting. As expected with the eligibility for patients in the program, the patient panels of program physicians had higher proportions of female patients and patients with Medicaid or no insurance compared to the patient panels of nonprogram physicians. Fewer program practices were using paper charts compared with nonprogram practices; however, more program practices were in transition to EMR.

Table 2 provides the breast and cervical cancer beliefs by program participation. Beliefs about the effectiveness of a screening tool or procedure in reducing breast or cervical cancer mortality did not differ significantly by program participation. Compared with nonprogram physicians, however, NBCCEDP physicians were less likely to report the very ef- fective response for all screening tools, with the exception of conventional Pap test. Overall, most program physicians believed that both CBE and breast self-examination (BSE) were somewhat effective, whereas mammograms for women $>50$ years of age, digital mammogram, LBC, and HPV test were believed to be very effective. The belief that guidelines are very influential did not differ statistically by program participation for breast or cervical cancer (data not shown). Overall, at least half of all physicians endorsed at least one set of guidelines as being very influential.

Breast and cervical cancer screening initiation, frequency, and cessation, by program participation, are presented in Table 3. There were no statistical differences noted by program participation. Use of new technologies, including digital mammography, LBC, and HPV testing, were examined by program participation and were found to be similar in use (data not shown).

\section{Discussion}

Provider participation in public programs is a timely topic, given slated increases in Medicaid eligibility under the Affordable Care Act. Although we observed differences in physician characteristics and practice settings, the beliefs and screening practices for both breast and cervical cancer were similar. Use of digital mammography, LBC, and HPV testing were similar by program participation. Additionally, similar proportions of program and nonprogram physicians made guideline-consistent recommendations for breast and cervical cancer screening initiation, frequency, and cessation.

We observed differences by specialty in program participation. As expected for women's cancer screening, more obstetrician/gynecologists reported participating in the NBCCEDP than not. There were fewer internal medicine providers reporting program participation than nonprogram participation.

Our finding that more program physicians practice in rural settings compared with nonprogram physicians reflects successful outreach to providers who serve women living in rural areas, a demographic group with high rates of both breast and cervical cancer and poor access to care. ${ }^{17,18}$ These findings are consistent with those of Saraiya et al., ${ }^{4}$ who found that program providers were well poised to serve those women at the highest risk of cervical cancer because they were more likely than nonprogram providers to serve racially diverse, uninsured, publicly insured, and rural patients.

The large number of physicians who reported don't know to NBCCEDP participation is of concern. This same finding was observed in the 2004 survey of NBCCEDP cervical cancer providers, in which $21 \%$ of providers reported that they were unsure of program participation. ${ }^{4}$ Reasons why providers might not know if they belong to the program could be that they were not directly involved with third-party payors or because NBCCEDP funds were integrated into more general women's health programs with different names. This finding suggests that the NBCCEDP, as the only national organized screening program that provides breast and cervical early detection services as well as case management, professional education, and quality assurances to underserved women, is not as well recognized as it should be, even 20 years after initiation. A recommendation to consider might be to highlight the program through national, state, and local meetings, 


Table 1. Physician and Practice Characteristics
by National Breast and Cervical Cancer
Early Detection Program Participation

$\begin{array}{lll}\begin{array}{l}\text { Physician characteristics } \\ \text { Age, years }\end{array} & & \\ <40 & 19.2(13.6-22.6) & 17.7(15.2-20.5) \\ 40-49 & 35.9(28.1-44.6) & 32.9(29.9-36.1) \\ 50-59 & 30.8(24.7-37.6) & 35.7(32.7-38.8) \\ \geq 60 & 14.1(9.7-20.1) & 13.7(11.6-16.1)\end{array}$

Gender* Male**

Race/ethnicity ${ }^{* a}$

$57.3(49.5-64.7) \quad 67.9(64.9-70.8)$

White, non-Hispanic ${ }^{* *} 77.5$ (70.5-83.2) 67.0 (63.6-70.3) Black, non-Hispanic

$7.2(4.2-12.0)$

$5.1(3.6-7.1)$

Hispanic

$5.5(2.7-10.8) \quad 6.7(5.0-9.1)$

Asian**

$7.7(4.5-12.8) \quad 16.9(14.4-19.8)$

International medical school graduate*

No

83.3 (76.4-88.4) $74.2(70.3-77.6)$

Years since medical school graduation $\geq 10$

Board certified

Yes

Specialty*

Family practice Internal medicine ${ }^{* *}$

General practice

Obstetrics/

$86.6(79.8-91.4) \quad 89.5(87.2-91.5)$

84.4 (78.6-88.9) 82.7 (80.2-84.9)

$50.8(43.2-58.3) \quad 43.7(40.4-46.9)$

$17.1(10.9-25.7) \quad 35.6(32.4-39.0)$

$6.2(3.6-10.5) \quad 2.8(1.9-4.1)$

$25.9(20.4-32.2) \quad 17.9(15.9-20.1)$ gynecology**

Medical school affiliation* $\mathrm{No}^{* *}$

$56.9(49.4-64.0) \quad 68.7(64.7-72.3)$

Practice characteristics

Practice type*

Solo practice ${ }^{* *}$

$13.7(8.9-20.5) \quad 30.1(27.1-33.4)$

Single specialty group 51.7 (43.5-59.9) $48.6(44.9-52.2)$

Multiple specialty $\quad 34.6(26.7-43.4) \quad 21.3(18.7-24.3)$ group**

Rural/urban location of practice ${ }^{* b}$

Urban**

Large rural ${ }^{* *}$

Small rural ${ }^{* *}$

60.9 (52.7-68.4) $85.7(83.5-87.8)$

$16.7(12.1-22.7) \quad 8.4(6.9-10.2)$

$22.4(15.9-30.7) \quad 5.8(4.4-7.6)$

Proportion of time spent providing primary care* $\geq 75 \%$ **

$61.0(53.2-68.3) 74.0(71.1-76.7)$

Percentage of female patients in practice* $<75 \%$ ***

$64.6(56.9-71.5) \quad 73.9(71.1-76.5)$

Main primary care practice setting*

Physician-owned $41.0(32.9-49.6) \quad 70.6$ (66.8-74.2) practice **

Employee of large

$21.5(15.3-29.2) \quad 14.8(12.3-17.7)$

medical group,

healthcare system, group or $\mathrm{HMO}$

Employee of university, hospital,

$37.5(30.3-45.3) \quad 14.5(11.9-17.7)$ or other clinic**

Percentage of patients insured by Medicaid* $\leq 25 \%$ ***

Percentage of patients uninsured*

$57.5(49.3-65.4) \quad 82.5(79.8-85.0)$ $\leq 25 \%$ ***

86.9 (80.6-91.4) $96.1(94.6-97.2)$

Any reminders to patients about screening

No (includes no 79.8 (72.8-85.4) $79.8(76.7-82.5)$ verbal reminders at visit)

(continued)
TABle 1. (CONTINUEd)

\begin{tabular}{|c|c|c|}
\hline Characteristic & $\begin{array}{c}Y e s \\
(\mathrm{n}=164)\end{array}$ & $\begin{array}{c}\text { No } \\
(\mathrm{n}=722)\end{array}$ \\
\hline \multicolumn{3}{|c|}{ Any reminders to physicians about screening } \\
\hline Yes & $65.2(57.6-72.2)$ & $59.2(55.5-62.9)$ \\
\hline \multicolumn{3}{|l|}{ Medical record system* } \\
\hline Paper charts** & $49.3(41.2-57.4)$ & $62.4(58.0-66.5)$ \\
\hline Partial EMR & $13.3(8.8-19.5)$ & $10.8(8.4-13.9)$ \\
\hline In transition to $\mathrm{EMR}^{* *}$ & $24.8(18.7-32.2)$ & $12.5(10.2-15.3)$ \\
\hline Full EMR & $12.6(7.9-19.3)$ & $14.3(11.6-17.5)$ \\
\hline
\end{tabular}

$n=1,111$ includes 27 missing program participation and 198 providers who reported don't know for program participation; these providers were different from those who reported yes to program providers: younger $(<40$ years, $33.3 \%)$, internist $(39.2 \%)$, urban practice $(81.2 \%)$, percentage of patients insured by Medicaid $(74.6 \%)$.

Estimates are weighted for selection probability and nonresponse.

${ }^{a}$ Race category does not sum to $100 \%$ because 3\% $(n=34)$ were other race.

${ }^{\mathrm{b}}$ Urban/rural defined using the Census tract-level Rural-Urban Commuting Area Codes.

${ }^{*}$ Chi-square test was significant $(p<0.05)$.

**t test was significant $(p<0.05)$.

EMR, electronic medical records; HMO, health maintenance organization.

prominent organizational websites, and other venues that cater to primary care providers.

There have been several other publications using these national survey data, ${ }^{19,20}$ including one by Yabroff et al., ${ }^{11}$ examining the overall findings of physician practices for cervical cancer screening. That study found that although most Pap test providers reported that screening guidelines were very influential, few had guideline-consistent recommendations for starting and stopping Pap screening across multiple vignettes. Our study also shows low adherence to guidelineconsistent recommendations for Pap testing for program and nonprogram physicians. This is especially important in light of the updated guidelines from ACOG to begin screening at 21 , regardless of sexual history, and to screen less often. ${ }^{6}$ In 2006-2007, when this survey was administered (before the updated guidelines), recommendations were to screen women by age 21 or within 3 years of sexual intercourse, whichever came first. However, $48 \%$ of program and $51 \%$ of nonprogram physicians reported they would screen an 18-year-old virgin. According to these results, implementations of interventions that focus on the harms of overscreening are needed to improve screening practices.

The USPSTF also updated its screening guidelines for breast cancer after this survey was administered. ${ }^{21}$ The new guidelines suggested that average-risk women could wait until age 50 to be screened and could be screened less often. However, both the ACS and ACOG continue to recommend annual screening for this group. ${ }^{12,13}$ According to our findings, $61 \%$ of program and $72 \%$ of nonprogram physicians would recommend annual mammography for a 40-49-year-old woman. With new updates and disagreement between organizational screening recommendations, these findings suggest there may be a need for interventions at both the provider and patient level to promote screening guideline adoption and adherence.

Despite the strengths of using a large, nationally representative sample with a high response rate and weighting for nonresponse, our study had several limitations. First, we had a 
Table 2. Breast and Cervical Cancer Screening Beliefs by National Breast and Cervical Cancer Early Detection Program Participation

\begin{tabular}{|c|c|c|}
\hline $\begin{array}{l}\text { Beliefs about the } \\
\text { effectiveness of...in } \\
\text { reducing cancer mortality }\end{array}$ & $\begin{array}{c}\text { Yes } \\
(\mathrm{n}=164)\end{array}$ & $\begin{array}{c}\text { No } \\
(\mathrm{n}=722)\end{array}$ \\
\hline \multicolumn{3}{|c|}{ Clinical breast examination } \\
\hline Very effective & $19.1(13.0-27.0)$ & $22.2(19.2-25.6)$ \\
\hline Somewhat effective & $63.7(55.0-71.6)$ & $64.0(60.2-67.6)$ \\
\hline Not effective & $13.4(8.9-19.5)$ & $9.7(7.8-12.0)$ \\
\hline \multicolumn{3}{|l|}{ Breast self-examination } \\
\hline Very effective & $20.8(14.8-28.4)$ & $23.7(20.5-27.1)$ \\
\hline Somewhat effective & $55.6(47.8-63.2)$ & $59.2(55.6-62.6)$ \\
\hline Not effective & $21.7(15.6-29.4)$ & $13.7(11.4-16.2)$ \\
\hline \multicolumn{3}{|c|}{ Mammogram for $40-49$ years of age } \\
\hline Very effective & $44.7(35.7-54.0)$ & $56.6(52.0-61.1)$ \\
\hline Somewhat effective & $50.3(41.3-59.2)$ & $39.8(35.6-44.2)$ \\
\hline Not effective & $2.9(1.0-7.5)$ & $2.0(1.2-3.5)$ \\
\hline \multicolumn{3}{|c|}{ Mammogram for $>50$ years of age } \\
\hline Very effective & $74.3(65.2-81.6)$ & $82.1(78.9-85.1)$ \\
\hline Somewhat effective & $24.6(17.4-33.5)$ & $17.5(14.7-20.7)$ \\
\hline Not effective & $0.9(0.1-5.8)$ & $0.2(0.0-1.2)$ \\
\hline \multicolumn{3}{|l|}{ Digital mammogram } \\
\hline Very effective & $65.1(55.3-73.8)$ & $71.9(67.8-75.6$ \\
\hline Somewhat effective & $22.3(15.8-30.3)$ & $21.3(18.0-24.9$ \\
\hline Not effective & 0 & $1.1(0.3-3.3)$ \\
\hline \multicolumn{3}{|l|}{ Conventional cytology } \\
\hline Very effective & $50.7(42.5-58.8)$ & $48.4(44.4-52.5)$ \\
\hline Somewhat effective & $46.5(38.9-54.1)$ & $49.8(45.7-53.9)$ \\
\hline Not effective & $2.5(0.9-6.9)$ & $1.5(0.9-2.4)$ \\
\hline \multicolumn{3}{|l|}{ Liquid-based cytology } \\
\hline Very effective & $85.1(75.6-91.3)$ & $85.6(82.5-88.3)$ \\
\hline Somewhat effective & $13.6(7.6-23.0)$ & $13.6(11.0-16.6)$ \\
\hline Not effective & $0.8(0.2-3.2)$ & $0.2(0-1.1)$ \\
\hline \multicolumn{3}{|c|}{ HPV DNA and cytology combined } \\
\hline Very effective & $73.8(66.1-80.2)$ & $74.9(71.7-77.8)$ \\
\hline Somewhat effective & $17.1(11.6-24.4)$ & $19.7(17.0-22.8)$ \\
\hline Not effective & $3.9(1.8-8.5)$ & $1.7(0.9-3.3)$ \\
\hline
\end{tabular}

$n=1,111$ includes 27 missing program participation and 198 providers who reported don't know for program participation; there was no difference in beliefs among these providers and those who reported yes to program participation. Estimates are weighted for selection probability and nonresponse.

The percentage of each category does not sum to $100 \%$ because those with missing values are included in total to calculate frequency $(<3 \%$ for all).

$p$ value testing difference between NBCCEDP participation and beliefs; no statistical difference reported.

$\mathrm{HPV}$, human papillomavirus.

large group of physicians who did not know if they participated in the NBCCEDP. This group was reported in Table 1 but was not included in statistical testing. Our observations may have been influenced by specialty rather than program affiliation; however, we were not able to examine specialty differences within the program because of limited sample size. We used standardized clinical vignettes to elicit physician screening practices, which may not reflect the diversity of women seen in clinical practice. However, the vignettes were cognitively tested among physicians before releasing the survey for use in the field. Finally, as with all surveys, reported practices may not reflect actual practices, which may be more accurately documented in medical record or billing data.
Table 3. Breast and Cervical Cancer Screening Initiation, Frequency, and Cessation by National Breast and Cervical Cancer Early Detection Program Participation

Yes
$(\mathrm{n}=164)$$\quad \begin{gathered}\text { No } \\ (\mathrm{n}=722)\end{gathered}$

Breast cancer screening

Recommend next mammogram for 40-49-year-old in good health in 12 months $^{\mathrm{a}} \quad 61.5(52.6-69.6) \quad 72.2(69.4-74.9)$ $>12$ months $^{\mathrm{a}} \quad 34.7(27.0-43.3) \quad 24.4(21.8-27.2)$ No mammogram $\quad 3.8(1.2-11.4) \quad 3.4(2.2-5.2)$

Recommend next mammogram for $\geq 50$ years in good health in $\begin{array}{lcc}12 \text { months }^{\mathrm{a}} & 97.3(92.9-99.0) & 97.5(96.1-98.4) \\ >12 \text { months } & 2.2(0.7-6.8) & 2.2(1.3-3.6) \\ \text { No mammogram } & 0.5(0.1-3.2) & 0.3(0.1-1.2)\end{array}$

Recommend next mammogram for $\geq 50$ years with lung cancer CBE only $\quad 9.7(5.8-15.6) \quad 12.3(10.1-14.8)$ Mammogram only $2.3(1.0-5.3) \quad 2.9(1.7-4.8)$ $\mathrm{CBE}$ and $44.1(34.9-53.6) \quad 43.8(40.2-47.4)$ mammogram

No screening $^{\mathrm{a}} \quad 44.0(35.7-52.6) \quad 41.2(37.2-44.9)$

Cervical cancer screening

Recommend Pap test for 18-year-old virgin Annually $\quad 32.1(24.3-41.2) \quad 33.3$ (29.7-37.1) > Annually $\quad 15.4(10.1-22.8) \quad 17.5(14.8-20.5)$ No cytology test ${ }^{\mathrm{a}} \quad 52.5(44.2-60.6) \quad 49.2(45.3-53.0)$

Recommend Pap test for 35-year-old with 3 normal cytology tests and no new sexual partners in 5 years $\begin{array}{lcc}\text { Annually } & 33.6(26.0-42.0) & 32.9(29.4-36.6) \\ >^{\text {Annually }} & 66.0(57.6-73.5) & 66.0(62.1-69.6) \\ \text { No cytology test } & 0.5(0.1-3.4) & 1.1(0.5-2.5)\end{array}$

Recommend Pap test for 35-year-old with hysterectomy for benign reasons

$\begin{array}{lcl}\text { Annually } & 6.5(3.5-11.7) & 11.8(9.5-14.6) \\ >\text { Annually } & 70.0(62.8-76.4) & 67.2(63.2-70.9) \\ \text { No cytology test }^{\mathrm{a}} & 23.5(17.8-30.4) & 21.0(17.9-24.5)\end{array}$

Recommend Pap test for 66-year-old with lung cancer, 3 normal cytology tests

$\begin{array}{lll}\text { Annually } & 14.9(10.3-21.0) & 12.4(10.3-14.9) \\ >\text { Annually } & 25.6(19.5-32.9) & 30.1(26.7-33.6) \\ \text { No cytology test }^{\text {a }} & 59.5(51.5-67.0) & 57.5(54.2-60.8)\end{array}$

$n=1,111$ includes 27 missing program participation and 198 providers who reported don't know for program participation; there were no differences in response compared to all other providers.

Estimates are weighted for selection probability and nonresponse. $p$ value testing difference between NBCCEDP participation and screening practices; no statistical difference reported

${ }^{a}$ Guideline consistent response for next screen.

$\mathrm{CBE}$, clinical breast examination.

\section{Conclusions}

These survey results provide a comparison of physician characteristics and screening practices by program participation for both cervical and breast (first-time reported) cancer. The survey demonstrated that participating physicians have experience with uninsured women in rural areas and have the same beliefs and practices in screening as their nonparticipating counterparts. Targeting awareness activities regarding the program and participation can ensure the referral of 
eligible patients into the programs and, ideally, more women being served.

\section{Acknowledgments}

Funding for this study was provided by NCI (contract N02PC-51308), CDC (interagency agreement Y3-PC-6017-01) and AHRQ (interagency agreements Y3-PC-5019-01 and Y3-PC5019-02).

The findings and conclusions in this report are those of the authors and do not necessarily represent the official position of the Centers for Disease Control and Prevention or the National Cancer Institute.

\section{Disclosure Statement}

The authors have no conflicts of interest to report.

\section{References}

1. Li CI. Racial and ethnic disparities in breast cancer stage, treatment, and survival in the United States. Ethnic Dis 2005;15(Suppl 2):S5-S9.

2. Yabroff KR, Lawrence WF, King JC, et al. Geographic disparities in cervical cancer mortality: What are the roles of risk factor prevalence, screening, and use of recommended treatment? J Rural Health 2005;21:149-157.

3. National Breast and Cervical Cancer Early Detection Program (NBCCEDP). Atlanta, GA: Centers for Disease Contro and Prevention, 2010. Available at www.cdc.gov/cancer/ nbccedp/about.htm Accessed June 17, 2010.

4. Saraiya M, Irwin KL, Carlin L, et al. Cervical cancer screening and management practices among providers in the National Breast and Cervical Cancer Early Detection Program (NBCCEDP). Cancer 2007;110:1024-1032.

5. Cooper CP, Saraiya M, McLean TA, et al. Report from the CDC. Pap test intervals used by physicians serving low-income women through the National Breast and Cervical Cancer Early Detection Program. J Womens Health 2005;14: 670-678.

6. American College of Obstetricians and Gynecologists. Practice bulletin No. 109: Cervical cytology screening. Obstet Gynecol 2009;114:1409-1420.

7. Cox JT. Human papillomavirus testing in primary cervical screening and abnormal Papanicolaou management. Obstet Gynecol Surv 2006;61(Suppl 1):S15-S25.

8. Lee $\mathrm{CH}$, Dershaw DD, Kopans D, et al. Breast cancer screening with imaging: Recommendations from the Society of Breast Imaging and the ACR on the use of mammography, breast MRI, breast ultrasound, and other technologies for the detection of clinically occult breast cancer. J Am Coll Radiol 2010;7:18-27.

9. Saslow D, Boetes C, Burke W, et al. American Cancer Society guidelines for breast screening with MRI as an adjunct to mammography. CA Cancer J Clin 2007;57:75-89.
10. National Survey of Primary Care Physicians' Recommendations and Practice for Breast, Cervical, Colorectal, and Lung Cancer Screening. Bethesda, MD: National Cancer Institute 2010. Available at healthservices.cancer.gov/surveys/screening_rp/ Accessed June 17, 2010.

11. Yabroff KR, Saraiya M, Meissner HI, et al. Specialty differences in primary care physician reports of Papanicolaou test screening practices: A national survey, 2006 to 2007. Ann Intern Med 2009;151:602-611.

12. American College of Obstetricians and Gynecologists. Practice bulletin No. 42: Clinical management guidelines for obstetrician-gynecologists. Breast cancer screening. Obstet Gynecol 2003;101:821-831.

13. Smith RA, Saslow D, Sawyer KA, et al. American Cancer Society guidelines for breast cancer screening: Update 2003. CA Cancer J Clin 2003;53:141-169.

14. Screening for breast cancer: Recommendations and rationale. Ann Intern Med 2002;137:344-346.

15. Saslow D, Runowicz CD, Solomon D, et al. American Cancer Society guideline for the early detection of cervical neoplasia and cancer. CA Cancer J Clin 2002;52:342-362.

16. U.S.Preventive Services Task Force. Screening for cervical cancer recommendations and rationale. Rockville, MD: Agency for Healthcare Research and Quality, 2003. AHRQ Pub. No. 03515A. Available at www.ahrq.gov/clinic/uspstf/uspscerv.htm

17. Coughlin SS, Thompson TD, Hall HI, Logan P, Uhler RJ. Breast and cervical carcinoma screening practices among women in rural and nonrural areas of the United States, 1998-1999. Cancer 2002;94:2801-2812.

18. Doescher MP, Jackson JE. Trends in cervical and breast cancer screening practices among women in rural and urban areas of the United States. J Public Health Manag Pract 2009;15:200-209.

19. Berkowitz Z, Saraiya M, Benard V, Yabroff KR. Common abnormal results of Pap and human papillomavirus cotesting: What physicians are recommending for management. Obstet Gynecol 2010;116:1332-1340.

20. Saraiya M, Berkowitz Z, Yabroff KR, Wideroff L, Kobrin S, Benard V. Cervical cancer screening with both human papillomavirus and Papanicolaou testing vs. Papanicolaou testing alone: What screening intervals are physicians recommending? Arch Intern Med 2010;170:977-985.

21. Screening for breast cancer: U.S. Preventive Services Task Force recommendation statement. Ann Intern Med 2009;151:716-726.

Address correspondence to: Vicki B. Benard, Ph.D. Epidemiology and Applied Research Branch Division of Cancer Control and Prevention Centers for Disease Control and Prevention 4770 Buford Highway, Mailstop K-55 Atlanta, GA 30341

E-mail: vbenard@cdc.gov 